\section{COMORBIDITY OF MIGRAINE IN CHILDREN PRESENTING WITH EPILEPSY TO A TERTIARY CARE CENTER}

Dorothee G. Kasteleijn-Nolst Trenite, Utrecht, the Netherlands; Vincenzo Belcastro, Como, Italy; Alberto Spalice, Pasquale Parisi, Rome: Kelley et al . confirmed the higher prevalence of migraine in children with epilepsy. ${ }^{1}$ The authors expanded upon our hypothesis ${ }^{2}$ by assuming that migraine would be more prevalent in patients with intractable epilepsy. In our opinion, this was not shown. In patients with intractable seizures, the focus is primarily on seizures vs headache complaints. Children with benign epilepsy with centrotemporal spikes and juvenile myoclonic epilepsy are most prevalent in this study and because these types of epilepsy are relatively benign, these patients are more likely to complain of headache. Considering that headache occurs after epilepsy onset and often in the same year confirms our hypothesis. $^{2}$

Comorbidity of migraine and epilepsy is especially prevalent in children, as shown by Kelley et al. and the articles they cited. In adults, this correlation is usually not found ${ }^{3}$ because adult patients who continue visiting the hospital generally are intractable and will underestimate their headache problems. Children show more autonomic manifestations.

The authors emphasized that there is underestimation of headache complaints especially in intractable children. We support their opinion and would like to add that the same is true for adults with intractable epilepsy.

Author Response: Sarah A. Kelley, Baltimore: We thank Kasteleijn-Nolst Trenite et al. for their comments. It is true that patients with more severe epilepsy may not bring up other complaints during a clinic visit. However, the way our study was designed, all patients with epilepsy (mild or severe) received a questionnaire asking them if they had headaches. All patients or their parents were therefore prompted to document headache on the questionnaire if the child had it.

C) 2013 American Academy of Neurology

1. Kelley SA, Hartman AL, Kossoff EH. Comorbidity of migraine in children presenting with epilepsy to a tertiary care center. Neurology 2012;79:468-473.

2. Parisi P, Piccioli M, Villa MP, Buttinelli C, Kasteleijn-Nolst Trenite DG. Hypothesis on neurophysiopathological mechanisms linking epilepsy and headache. Med Hypotheses 2008;70:1150-1154.

3. Tonini MC, Giordano L, Atzeni L, et al; EPICEF Group. Primary headache and epilepsy: a multicenter cross-sectional study. Epilepsy Behav 2012;23:342-347.

4. Belcastro V, Striano P, Kasteleijn-Nolst Trenite DG, Villa MP, Parisi P. Migralepsy, hemicrania epileptica, post-ictal headache and "ictal epileptic headache": a proposal for terminology and classification revision. J Headache Pain 2011;12:289-294.

\title{
CORRECTION
}

\section{Subjective cognitive impairment: Fickle but fateful}

In the editorial "Subjective cognitive impairment: Fickle but fateful" by D.S. Knopman (Neurology ${ }^{\circledR}$ 2012;79:1308-1309), in lines 15-19 of the second column on page 1308, the text should read as follows: "The authors defined SMI using a single question 'Do you feel like your memory is becoming worse?' Participants who answered 'Yes, this worries me' were classified as having SMI." The author regrets the error.

\section{Default-mode network dysfunction and cognitive impairment in progressive MS}

In the article "Default-mode network dysfunction and cognitive impairment in progressive MS" by M.A. Rocca et al. (Neurology ${ }^{\circledR}$ 2010;74:1252-1259), there is an error in the title of table 3, which should read "Mean (SE) values of $z$ scores of resting state activity within the clusters showing a significant difference among healthy controls, patients with SPMS, and patients with PPMS." The values within the table are correct. The authors regret the error. 


\section{Neurology}

\section{Default-mode network dysfunction and cognitive impairment in progressive MS Neurology 2013;80;421}

DOI 10.1212/WNL.0b013e3182817f5f

\section{This information is current as of January 21, 2013}

\section{Updated Information \&} Services

Permissions \& Licensing

\section{Reprints}

including high resolution figures, can be found at: http://n.neurology.org/content/80/4/421.3.full

Information about reproducing this article in parts (figures,tables) or in its entirety can be found online at:

http://www.neurology.org/about/about_the_journal\#permissions

Information about ordering reprints can be found online:

http://n.neurology.org/subscribers/advertise

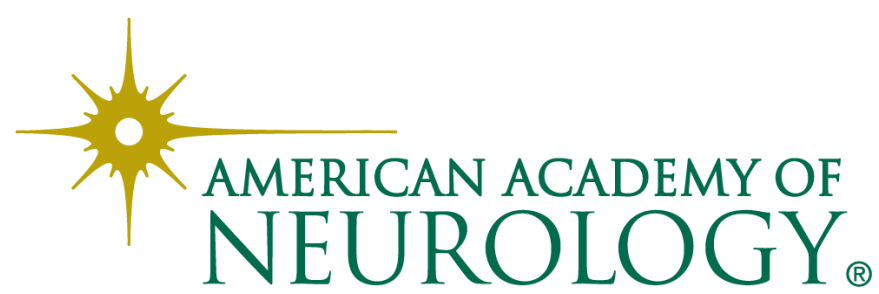

